\title{
Pars Plana Lensectomy Combined with Pars Plana Vitrectomy in Traumatic Ectopia Lentis
}

\section{Dilek Yasa}

Prof. Dr. N. Resat Belger Beyoglu Eye Training and Research Hospital, Istanbul, Turkey

\begin{abstract}
Objectives: The aim of the present study was to report the outcomes of pars plana lensectomy (PPL) combined with pars plana vitrectomy (PPV) in traumatic ectopia lentis performed at a tertiary eye hospital.

Methods: Patients who underwent PPL combined with PPV for surgical management of traumatic lens subluxation/ dislocation in the clinic were retrospectively evaluated. Only patients with at least 6 months follow-up were included in the study.

Results: Sixteen eyes of 16 patients were included in the study. Of the total, $94 \%$ of the patients were male and $6 \%$ were female. The mean age of the patients was $4 I \pm 17$ years. The mean length of follow-up was $9 \pm 5$ months. At presentation, $19 \%$ of the patients had intravitreal hemorrhage and $38 \%$ had retinal detachment. Preoperatively, $19 \%$ of the patients had $5 / 200$ or better visual acuity. At the final visit, visual acuity was "hand motion" or better in all patients, and $38 \%$ of the patients had 5/200 or better visual acuity. Visual acuity was stable or improved in all patients. Anatomical success was achieved in all patients who had retinal detachment preoperatively.

Conclusion: PPL combined with PPV is a safe and effective method of surgical management of traumatic ectopia lentis; however, the associated pathologies determine the final visual outcome and preoperative visual acuity is the most important prognostic factor.
\end{abstract}

Keywords: Crystalline lens, dislocation, pars plana lensectomy, pars plana vitrectomy, subluxation, trauma.

\section{Introduction}

Ectopia lentis is displacement of the crystalline lens from its normal location (I). When the lens is completely outside the patellar fossa (e.g., on the retina, in the anterior chamber, or free-floating in the vitreus) it is called lens dislocation. If the lens is malpositioned but it is still at least partially in the patellar fossa then it is called a lens subluxation. Ectopia lentis may result in a decrease in visual acuity and complications such as glaucoma or cataract (2).

Hereditary or systemic diseases are frequent causes of ectopia lentis; however, the most common cause is trauma (2). Traumatic lens dislocation may or may not be accompanied by other traumatic pathologies such as cataract, intra- ocular foreign body, hyphema, intravitreal hemorrhage, or retinal detachment. Pars plana vitrectomy (PPV) combined with pars plana lensectomy (PPL) provides a means for management of posterior segment complications as well as removal of the dislocated or subluxated crystalline lens, when indicated (3).

This study is a retrospective case series from a tertiary eye center, presented to describe the clinical features and surgical outcomes of PPL combined with PPV for surgical management of traumatic ectopia lentis.

\section{Methods}

This study followed the tenets of the Declaration of Helsin- 
$\mathrm{ki}$, and approval was obtained from the appropriate institutional review board. The medical records of patients who had traumatic ectopia lentis and underwent PPL combined with PPV were retrospectively analyzed. Only patients with at least 6 months of follow-up were included in the study. Patients who had previous ocular pathologies, patients with unknown visual acuity at presentation or at the final visit, and patients whose surgical records were incomplete were excluded. The age and gender of the patients, trauma classification, follow-up time, presenting and final visual acuity, intraocular pressure, other anterior and posterior segment examination findings, and postoperative complications were obtained from the patients' records.

Visual acuity was classified into 7 groups: no light perception (NLP), light perception (LP), hand motion at $30 \mathrm{~cm}$ $(\mathrm{HM})$, and counting fingers at $30 \mathrm{~cm}$ to $<5 / 200,5 / 200$ to $<20 / 200,20 / 200$ to $<20 / 40$, and $20 / 40$ or better. The trauma type was classified according to Birmingham Eye Trauma Terminology system (4). Elevated intraocular pressure was defined as intraocular pressure (IOP) of $>25 \mathrm{mmHg}$, and hypotony was defined as IOP of $\leq 5 \mathrm{mmHg}$. Ambulatory vision was defined as visual acuity $\geq 5 / 200$. In patients with traumatic retinal detachment, functional success was defined as visual acuity $\geq 5 / 200$, and anatomical success was defined as complete attachment of the retina at the final visit.

\section{Surgical Technique}

All cases were operated on with standard 23-G vitrectomy techniques using the Constellation Surgical Vitrectomy System (Alcon Laboratories Inc., Fort Worth, TX, USA). PPL was performed on eyes with subluxation/dislocation. A core vitrectomy was performed to remove media opacity and perfluorocarbon liquids were used to protect the macula. After vitreous adhesions on the dislocated/subluxated crystalline lens were removed, the lens material itself was lifted and removed from the central vitreous. If retinal detachment was present, perfluorocarbon liquids were used to attach the retina. Peripheric indentation was applied in all patients to look for retinal breaks, which were treated with photocoagulation delivered with an endolaser. A scleral buckle was used when indicated, and additional surgical procedures, such as membrane peeling, retinotomy, or retinectomy, were performed when indicated. Sclerotomies were sutured at the end of the surgery.

\section{Statistical Analysis}

Categorical variables were analyzed using a chi-square and Fisher's exact test. Nonparametric variables were compared using the Mann-Whitney $U$ test. A two-tailed $p$ value of less than 0.05 was considered statistically significant. SPSS Statistics for Windows, Version I7.0 (SPSS Inc., Chicago, IL, USA) was used for the statistical analysis.

\section{Results}

Patient characteristics and trauma type are presented in Table I. The associated pathologies can be seen in Table 2 . Additional surgical procedures are provided in Table 3. Eight $(50 \%)$ patients had primary saturation before the operation.

Table I. Patient characteristics and type of trauma

\begin{tabular}{lc} 
Gender, No. (\%) & \\
Male & $\mathrm{I} 5(94)$ \\
Female & $\mathrm{I}(6)$ \\
Age (years) & \\
Mean \pm SD & $4 \mathrm{I} \pm 17$ \\
Median (Range) & $(18-74)$ \\
Trauma type, No. (\%) \\
Open \\
Closed & $10(63)$ \\
\hline
\end{tabular}

Table 2. Associated ocular pathologies

\begin{tabular}{lc} 
Ocular pathology & $\mathbf{n}(\%)$ \\
\hline Hyphema & $2(13)$ \\
Cyclodialysis/iridodialysis & $2(13)$ \\
Corneal edema & $3(19)$ \\
Intravitreal hemorrhage & $3(19)$ \\
Glaucoma & $2(13)$ \\
Suprachoroidal hemorrhage & $3(19)$ \\
Choroidal detachment & $4(25)$ \\
Retinal detachment & $6(38)$ \\
Endophthalmitis & $1(6)$ \\
\hline
\end{tabular}
n: number,

Table 3. Additional surgical procedures

\begin{tabular}{lc} 
Surgical procedure & $\mathbf{n}(\%)$ \\
\hline Scleral buckle & $2(13)$ \\
Retinotomy & $2(13)$ \\
Retinectomy & $3(19)$ \\
Barrier suture & $2(13)$ \\
Endotamponade & \\
$\quad$ Silicone oil (1000 cs) & $3(6)$ \\
$\quad$ Silicone oil (5000 cs) & $4(6)$ \\
$\quad$ SF 6 & I (I9) \\
$\quad$ C3F8 & I (25) \\
\hline cs: centistoke; C3F8: perfluoropropane; n: number; SF6: sulfur hexafluoride.
\end{tabular}


Table 4. Factors associated with anatomical and functional success

\begin{tabular}{lccc} 
& \multicolumn{2}{c}{ Ambulatory vision } & \\
\cline { 2 - 3 } & $\mathbf{n}$ & $\mathbf{n}(\%)$ & $\mathbf{p}^{*}$ \\
\hline Injury type & 10 & $3 / 10(30)$ & 0.60 \\
$\quad \begin{array}{l}\text { Open globe trauma } \\
\text { Closed globe trauma }\end{array}$ & 6 & $3 / 6(50)$ & \\
Intraocular foreign body & & & \\
$\quad$ Present & 5 & $5 / 6(83)$ & 0.39 \\
$\quad$ Absent & 11 & $17 / 25(68)$ & \\
Presenting DCVA & & & \\
$\quad \geq 5 / 200$ & 3 & $3 / 3(100)$ & 0.036 \\
$\quad<5 / 200$ & 13 & $3 / 13(23)$ & \\
Retinal detachment & & & \\
$\quad$ Present & 6 & $1 / 6(17)$ & 0.31 \\
$\quad$ Absent & 10 & $5 / 10(50)$ & \\
Intravitreal hemorrhage & & & \\
$\quad \begin{array}{l}\text { Present } \\
\text { Absent }\end{array}$ & 3 & $0 / 3(0)$ & 1.00 \\
\hline
\end{tabular}

DCVA: distance corrected visual acuity; n: number.

*: Fisher's exact test, two-tailed $p$ value.

The association of various preoperative factors with postoperative ambulatory vision $(\geq 5 / 200)$ are presented in Table 4. Preoperative visual acuity of $5 / 200$ or better was the only factor that was significantly associated with postoperative ambulatory vision (Table 4). Preoperative and postoperative cumulative distance corrected visual acuities are presented in Figure I. At the final visit, visual acuity was HM or better in all patients and $38 \%$ of the patients had $5 / 200$ or better visual acuity. Visual acuity was stable or improved in all patients. Anatomical success was achieved in all patients who had preoperative retinal detachment.

Two patients had preoperative glaucoma, and postoperative glaucoma developed in I patient. In all 3 patients, the
IOP was under control with medical treatment at the last visit. In I patient with endophthalmitis at presentation, retinal detachment occurred during follow-up. A second PPV surgery was performed on this patient, and although the visual acuity was only $\mathrm{HM}$, the retina was completely attached at the last follow-up.

\section{Discussion}

In this study, the clinical features and surgical outcomes of 23-G PPV in the surgical management of traumatic ectopia lentis were evaluated. We found that middle-aged males constituted most of our patients; the male to female ratio was $15: 1$ in this series. Considering that trauma is more common in males of working age (5), a male dominance in traumatic ectopia lentis is not surprising.

Traumatic eye injuries may present with a great diversity of clinical pictures, as the nature of the trauma may be different in each patient. Most of the patients in this retrospective case series had severe anterior and posterior segment complications in addition to ectopia lentis. Our hospital is a tertiary referral hospital and usually the most severely traumatized eyes are referred to our clinic. As a result, most of the patients in this study had open globe trauma and $38 \%$ of the patients had traumatic retinal detachment. In a similar series of 20 patients who underwent PPL combined with PPV, Ünver et al. (6) reported that $30 \%$ of their patients had open globe trauma and $30 \%$ had retinal detachment, similar to our experience. None of the patients in this study had a decline in visual acuity postoperatively when compared with preoperatively, however, severe anterior and posterior segment complications limited visual gains in most of our patients, and only $19 \%$ of them had distance corrected visual acuity of $20 / 40$ or more.

The association between several factors and postoperative visual acuity was analyzed. It is well described in the literature that the most important prognostic factor in traumatic eyes is preoperative visual acuity $(6,7,8)$. In agreement with the literature, the results of this study indicated that

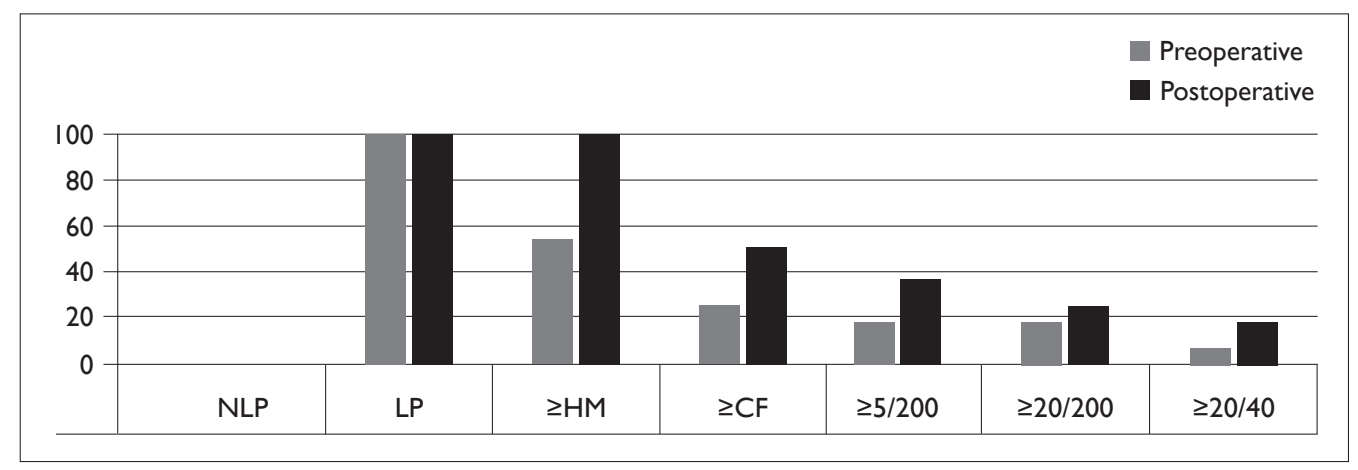

Figure I. Preoperative and postoperative cumulative distance-corrected visual acuity.

NLP: No light perception; LP: No light perception; HM: Hand motion; CF: Counting fingers. 
postoperative ambulatory vision was more common in eyes with a presenting visual acuity of 5/200 or more. The Ocular Trauma Score (OTS) developed by Kuhn et al. (9) is widely used to predict visual outcome after traumatic eye injuries. Kuhn et al. evaluated more than 100 variables to develop the OTS. This scoring system determines an initial sum of positive raw points based on presenting visual acuity, and the presence of retinal detachment, open globe trauma (rupture or penetrating trauma), endophthalmitis, or afferent pupillary defect adds negative raw points. In this study, although ambulatory vision was more common in patients with closed globe trauma ( $50 \%$ vs $30 \%$ ) and no retinal detachment $(50 \%$ vs $17 \%$ ), the difference in the rates did not reach statistical significance. Although we did not observe a statistically significant difference, a study with a larger number of patients might see a difference in the functional success rates of these groups. Endophthalmitis was present in only I patient in our study. This patient's visual acuity was LP at presentation and $\mathrm{HM}$ at the final visit. Endophthalmitis is expected to decrease final visual acuity in an already traumatized eye, and visual acuity was limited in this patient.

The most important weakness of this study is its retrospective nature and the small number of patients. If more patients had been included, the power of the statistical analysis would be greater. In other words, although this study demonstrates the value of preoperative visual acuity, it is not possible to draw conclusions about the factors for which we did not find a statistically significant prognostic value. The retrospective design of this study is a disadvantage when reporting data such as trauma history, preoperative findings, or postoperative complications because patient records were not designed for traumatic eyes and may not contain sufficient detail.

There is an inherent difference in trauma patients in different parts of the world, and even different parts of the same country. Despite its weaknesses, this study usefully reflects the patient demographics and surgical outcomes of a tertiary reference eye hospital in Turkey. It also highlights the importance of preoperative visual acuity.

In conclusion, in this study, we presented the clinical features of traumatic ectopia lentis patients at a tertiary eye hospital in Turkey and analyzed the association with visual outcome after combined PPL and PPV. We found that PPL combined with PPV is a safe and effective method in terms of anatomical success. However, although vision was stabilized or improved after surgery, the pathologies associated with the initial trauma limit visual outcomes. Ambulatory vision was achieved in only one-third of the patients, and it was more common among patients with a preoperative visual acuity of $5 / 200$ or more.

Acknowledgements: I would like to thank Zeynep Gizem Erdem, MD for her assistance with the collection of data.

\section{Disclosures}

Peer-review: Externally peer-reviewed.

Conflict of Interest: The authors declare that there is no conflict of interest regarding the publication of this article.

\section{References}

I. Jarrett WH II. Dislocation of the lens. A study of 166 hospitalized cases. Arch Ophthalmol 1967;78:289-96. [CrossRef]

2. Greven CM, Collins AS, Slusher MM, Weaver RG. Visual results, prognostic indicators, and posterior segment findings following surgery for cataract/lens subluxation-dislocation secondary to ocular contusion injuries. Retina 2002;22:575-80. [CrossRef]

3. Marcus DM, Topping TM, Frederick AR Jr. Vitreoretinal management of traumatic dislocation of the crystalline lens. Int Ophthalmol Clin 1995;35:139-50. [CrossRef]

4. Kuhn F, Morris R, Witherspoon CD, Heimann K, Jeffers JB, Treister G. A standardized classification of ocular trauma. Ophthalmology 1996;103:240-3. [CrossRef]

5. Kıvanç SA, Akova Budak B, Skrijelj E, Tok Çevik M. Demographic Characteristics and Clinical Outcome of Work-related Open Globe Injuries in the Most Industrialised Region of Turkey. Turk J Ophthalmol 2017;47: 18-23. [CrossRef]

6. Unver YB, Kapran Z, Acar N, Altan T. Ocular trauma score in open-globe injuries. J Trauma 2009;66:1030-2. [CrossRef]

7. Unver YB, Acar N, Kapran Z, Altan T. Prognostic factors in severely traumatized eyes with posterior segment involvement. Ulus Travma Acil Cerrahi Derg 2009;15:27|-6.

8. Nowomiejska K, Choragiewicz T, Borowicz D, Brzozowska A, Moneta-Wielgos J, Maciejewski R, et al. Surgical Management of Traumatic Retinal Detachment with Primary Vitrectomy in Adult Patients. J Ophthalmol 2017;2017:5084319. [CrossRef]

9. Kuhn F, Maisiak R, Mann L, Mester V, Morris R, Witherspoon CD. The Ocular Trauma Score (OTS). Ophthalmol Clin North Am 2002;15:163-5. [CrossRef] 